\title{
BMJ Open Association between health service utilisation of internal migrant children and parents' acculturation in Guangdong, China: a cross-sectional study
}

Bo-li Peng, ${ }^{1}$ Guan-yang Zou, ${ }^{1,2}$ Wen Chen, ${ }^{1,3}$ Yan-wei Lin, ${ }^{1,3}$ Li Ling ${ }^{1,3}$

To cite: Peng B, Zou G, Chen W, et al. Association between health service utilisation of internal migrant children and parents' acculturation in Guangdong, China: a crosssectional study. BMJ Open 2018;8:e018844. doi:10.1136/ bmjopen-2017-018844

- Prepublication history for this paper is available online. To view these files, please visit the journal online (http://dx.doi. org/10.1136/bmjopen-2017018844).

B-P and G-Z contributed equally.

Received 25 July 2017

Revised 21 November 2017

Accepted 22 November 2017

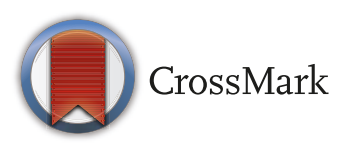

${ }^{1}$ Center for Migrant Health Policy, Sun Yat-sen University, Guangzhou, China

${ }^{2}$ Institute for International Health and Development, Queen Margaret University, Edinburgh, UK

${ }^{3}$ Faculty of Medical Statistics and Epidemiology, School of Public Health, Sun Yat-sen University, Guangzhou, China

Correspondence to

Dr Li Ling;

lingli@mail.sysu.edu.cn

\section{ABSTRACT}

Objectives To assess the health service utilisation of internal migrant children in Guangdong, China, and to explore the association between children's health service utilisation and their parents' acculturation.

Design Cross-sectional survey between April and May 2016.

Setting Six society-run schools of Tianhe and Baiyun districts in Guangzhou City of China.

Participants We recruited all students at grade 7 or 8 and one of their parents who resided in Guangzhou over 6 months without permanent registered residence (hukou) in Guangzhou (1161 pairs completed this survey). 258 children were ill within the past 2 weeks or during the last year.

Main outcome measures The main outcome was self-reported health service utilisation. Logistic regression analysis was conducted to explore the association between children's unmet needs for outpatient or inpatient service and their parents' acculturation (categorised into high, middle and low groups).

Results In total, 216 children, or $18.6 \%$ of the total subjects, were ill within the past 2 weeks and were in need of outpatient service; 94 children, or $8.1 \%$ of the total subjects, were in need of inpatient service. Among them, $17.6 \%$ and $46.8 \%$ of the migrant children had unmet needs for outpatient and inpatient services, respectively. After controlling for enabling resources and predisposing characteristics, migrant children with parents in the middle-acculturation group (adjusted $\mathrm{OR}=3.17$, $95 \%$ Cls 1.2 to $8.3, P<0.05$ ) were more likely to have an unmet outpatient need than high-acculturation or lowacculturation groups, although only statistically significant when comparing with the high-acculturation group. Stratified analysis suggested that this association could be moderated by their family economic status.

Conclusions Our study suggested that the association between migrant children's health service utilisation and their parents' acculturation was complex and could be moderated by family economic status. Increasing the service utilisation among migrant children requires improving the acculturation and economic status of the parents of internal migrants.
Strengths and limitations of this study

- This is the first of its kind study on the association between internal migrant children's health service utilisation and their parents' acculturation.

- This study measured parents' acculturation more comprehensively by using a synthetic variable calculated from a multidimensional questionnaire, and parents' acculturation in this study was evaluated by a categorical variable.

- This study explored the moderation of family economic status on the association between internal migrant children's health service utilisation and parents' acculturation.

- This cross-sectional study cannot explore the causal relationship between children's health service utilisation and their parent's acculturation.

- The health service utilisation was measured by selfreported questions that might have reported bias of health conditions and utilisation.

\section{INTRODUCTION}

With rapid economic development in China, internal migrants (IMs), a population that has been living in a place other than their officially registered residence (hukou) for at least 6 months, ${ }^{1}$ has become increasingly popular in some developed cities. This population was up to 221 million in 2010 in China, among whom there were 35.8 million $(16.2 \%)$ IM children under 18 years old, ${ }^{2}$ and its number has continued to rise since then. The hukou system in China divided resident status into rural and urban residency. Since the social welfare system is tied to (administrated and funded by) the local governments, the hukou in China is associated with the local social welfare, such as housing, children's education, stable working, health insurance and public health services. ${ }^{3}$

IMs in China tend to have poorer economic status with overtime working ${ }^{4}$; they are 
underinsured and have to return to permanent registered residence for medical care so as to receive reimbursement ${ }^{5}$; and they have limited access to a range of public services ${ }^{6}$ provided by the government, including the health services, ${ }^{7-10}$ due to their lack of local household registration. The utilisation of prenatal examinations and postnatal visit among IMs was about twice and six times as low as that of the local residents, respectively. ${ }^{9}$ The IMs were about two times less likely to use hospitalisation service than the local residents. ${ }^{11}$

Similarly, studies found that international immigrant children tended to be in poorer access to health service utilisation (HSU) compared with their native counterparts. ${ }^{12-14}$ A study in the USA showed that $6 \%$ of the local family's children had no usual source of healthcare, compared with a percentage of as high as $26 \%$ among the international immigrant children. ${ }^{15}$ Previous studies on HSU among international immigrant children have reported that parents' acculturation, conceptualised as the international immigrants' ability of adaption to the attitudes, beliefs, values, customs and behaviours of a new or different culture, ${ }^{16}{ }^{17}$ was an important factor for the HSU of their immigrant children.

However, results on the association between international immigrant children's HSU and their parents' acculturation did not allow drawing the final conclusion. Most of these studies have demonstrated positive associations between these two variables. ${ }^{18-23}$ This was because international immigrant children in more acculturated families tended to be more insured and have better access to native healthcare system. ${ }^{19}$ In addition, more acculturated parents usually acquired better English proficiency, which enabled fluent communications with local health providers and thus better HSU. ${ }^{23}$ However, some studies did not find any association between HSU and certain indicators of acculturation, such as mothers' language proficiency and length of residence. ${ }^{1821}$ This was because parents' limited English proficiency was not associated with insurance coverage, which was however positively associated with international immigrant children's HSU. ${ }^{18}$ To measure the acculturation, the majority of studies employed indicators including local born, mothers' language preference and length of residence ${ }^{2021}$; among them, the language proficiency was most frequently mentioned. Few studies have measured acculturation by multidimensional scales, for example, using the Marin's Short Acculturation Scale for Hispanics ${ }^{19} 24$ (which evaluated language competence, cultural identity and cultural competence) and the acculturation scale ${ }^{22}$ (which comprised questions about language, ethnic identification and nativity).

Like international immigrants, the IM parents also experience acculturation, since most of them have migrated from rural to urban areas of China where the economic development, culture and social environment are very diverse. For instance, compared with urban areas in China, rural areas are less developed, with fewer working opportunities, education resources, limited access to health facilities and poor quality in health service. ${ }^{3}$ Previous research in China measured the IMs' acculturation by language/dialect use (separation state), friendship development (integration state), self-identity (marginalisation state) and lifestyle (assimilation state) ${ }^{25}$ based on Berry's acculturation theory. ${ }^{26}$ Yang $^{27}$ and Zhou $^{28}$ divided the acculturation into four dimensions (relating to culture, social, structure and identity) and built an index system of IMs' acculturation.

Most of the previous studies on HSU among IMs have focused on adults. IM children are currently under research, while limited access to health service would affect their health and school performance. ${ }^{29}$ Little is also known about HSU of IM children in China, as well as the association between IM children's HSU and their parents' acculturation. This study adopts the Anderson's Behaviour Model of Health Services Utilization, a popular model to analyse factors associated with the HSU. The model divided these factors associated with HSU into three dimensions, namely, predisposing characteristics, enabling resources and needs. ${ }^{30}$ The predisposing characteristics included demographic factors, social structure and health belief. The enabling resources included financial and social resources. Among these factors, enabling resources, such as income, health insurance and time, was mutable and profoundly associated with the HSU. ${ }^{31}$ Acculturation is somehow similar to the social structure in the dimension of predisposing characteristics. ${ }^{32}$ The Anderson's behaviours model has been widely used in studies on factors associated with HSU, ${ }^{30-32}$ including IMs' HSU. ${ }^{33-36}$

Drawing from the studies on international immigrants, we hypothesise that the IM children would also have poor health access, and their service utilisation is positively associated with their parents' acculturation.

This paper measures the HSU of the IM children and explores the association between IM children' HSU and parents' acculturation in Guangzhou, China. Through this study, we hope to identify the barriers of the HSU of the IM children and the strategies to meet their demands, thus improving the health equity between IMs and the local residents.

\section{METHODS}

\section{Setting and sampling}

This was a cross-sectional survey conducted in Tianhe and Baiyun Districts in Guangzhou City, Guangdong province of China, between April and May in 2016. Guangzhou is one of the top three metropolises and one of the main destinations of IMs in China. With 54.2 million IMs, ${ }^{37}$ Guangzhou ranked the fifth in terms of the number of IMs among all cities in China. ${ }^{1}$ Tianhe and Baiyun Districts were selected for this study because they had the most IM in Guangzhou. ${ }^{38}$

\section{Participants}

Since most of the IM children are often excluded from studying in the public schools due to their hukou status, 
we decided to recruit study participants from three society-run secondary schools in each district. Society-run schools were similar to the private secondary schools but somewhat different because they provided education to IM children who were excluded from the public schools in Guangzhou. We recruited all the seventh and eighth grade students in the study schools that met the following inclusion criteria: (1) holding a permanent household registration (hukou) other than Guangzhou but having lived in Guangzhou for at least 6 months, (2) at least one of their parents/caregivers did not have Guangzhou hukou, (3) living with at least one parent/caregiver and (4) having provided a signed informed consent form by their parent/caregivers.

\section{Data collection}

A self-administered questionnaire was completed by both the student and his/her caregiver. Investigators (postgraduate and undergraduate students) from Sun Yat-sen University were trained to conduct the questionnaire survey. The trained investigators guided the students in the society-run schools to complete their section of the questionnaire and trained the students who received the survey to guide their caregiver to complete caregiver's section. The investigators also conducted quality control such as checking logic mistakes and corrected any errors as soon as possible.

The questionnaire section completed by caregiver included information of students' HSU, caregivers' acculturation and potential influencing factors drawn from the Anderson's Behaviour Model of Health Services Utilization, comprising predisposing characteristics, enabling resources and needs. ${ }^{30} 31$ The predisposing characteristics included demographic factors (age and marital status), social structure (education level) and health belief (measured by a proxy index of physical check-up during the past year, since better health belief predicted better preventative health behaviours, ${ }^{39} 40$ including more physical check-up, ${ }^{32}$ according to the health belief model). The enabling resources included information about families' economic status, whether parents had to work during the opening hours of health facilities and children's health insurance status. Regarding the children's needs for outpatient and inpatient services, we collected self-reported illnesses in the last 2 weeks (for outpatients) and last year (for inpatients). In the questionnaire section for children, we collected demographic factors (children's age and gender) and social structure (whether living with children's grandparents), which were also part of the predisposing characteristics.

\section{Measurements}

The dependent and independent variables were based on the Anderson's Behaviour Model of Health Services Utilization.

\section{Dependent variables}

The outcome variable was IM children's HSU, which was measured by the self-reported questions for caregivers, including the children's outpatient service utilisation within the past 2 weeks and hospitalisation during the last year.

\section{Independent variables}

\section{Needs}

IM children's health service needs were measured by questions about whether your children fell ill within the past 2 weeks ('outpatient need') or whether they were asked to be hospitalised by a doctor during the last year ('inpatient need'), which included both hospitalised and nonhospitalised ones. The unmet need for outpatient service referred to the proportion of children who got ill within the past 2 weeks but did not visit a doctor, while the unmet need of inpatient service was defined as the proportion of children who were asked to be hospitalised but did not use it during the past year. We only chose the children who were in need (including those who used or had an unmet HSU need) for analysis.

\section{Acculturation}

As to parents' acculturation, we referred to the existing acculturation scales of Berry, Birman and Trickett, Szapocznik et al and Zhang ${ }^{26}{ }^{41-43}$ and the index system raised by $\mathrm{Yan}^{27}$ and Zhou. ${ }^{28}$ The questionnaire comprised 27 questions and could be divided into four dimensions, ${ }^{25}$ namely, language proficiency, lifestyle integration (including dressing, dietary habits and entertainment and social customs integration), social interaction and self-identity. We have conducted a preliminary investigation before $(n=136)$, which showed an acceptable reliability (the Cronbach's alpha was 0.678 ). The main survey's reliability test of questions relating to the four dimensions suggested the Cronbach's alpha being $0.628,0.635,0.773$ and 0.393 , respectively, and Cronbach's Alpha of the total acculturation was 0.783 . Table 1 illustrated the questions in relation to the four dimensions.

In order to evaluate parents' acculturation status, we conducted a factor analysis to calculate a synthetic score of acculturation first and then employed the min-max normalisation and percentage method to make sure that the synthetic score was between 0 and 100 , with an average score of 50 points. Then we trisected parents' acculturation status: low-acculturation group, middle-acculturation group and high-acculturation group, according to the trisectional quantile of all 1161 IM parents' acculturation scores (cut by 46.62 and 61.41).

\section{Predisposing characteristics}

Information on predisposing characteristics collected was described in the section of data collection.

\section{Enabling resources}

Information of enabling resources collected was also described in the section of data collection. Besides, children's families' economic status was also a synthetic score, which was calculated from variables of family monthly income, occupation and residence type by the same 


\begin{tabular}{|c|c|c|}
\hline Dimensions & Questions & Means \pm SD \\
\hline \multirow[t]{6}{*}{ Language proficiency } & Which kind of language do you speak most? & $2.21 \pm 1.48$ \\
\hline & Can you understand Cantonese? & $4.01 \pm 1.34$ \\
\hline & Can you speak Cantonese? & $2.93 \pm 1.61$ \\
\hline & Can you understand Mandarin? & $4.83 \pm 0.53$ \\
\hline & Can you speak Mandarin? & $3.66 \pm 1.27$ \\
\hline & Which language do you speak most in your current residence? & $3.18 \pm 1.46$ \\
\hline \multicolumn{3}{|l|}{ Lifestyle integration } \\
\hline \multirow[t]{5}{*}{ Social customs } & Are you familiar with the local customs of wedding and funeral? & $1.98 \pm 0.97$ \\
\hline & Will you follow the local customs of wedding and funeral? & $2.68 \pm 1.20$ \\
\hline & Do you return during the spring festival? & $2.15 \pm 1.23$ \\
\hline & If you can choose, will you return during the spring festival? & $1.50 \pm 1.00$ \\
\hline & $\begin{array}{l}\text { If you can choose, would you like to celebrate the spring festival following the customs } \\
\text { of Guangzhou? }\end{array}$ & $2.20 \pm 1.05$ \\
\hline \multirow[t]{2}{*}{ Dressing } & Do you think natives' dressing in Guangzhou is more beautiful? & $3.35 \pm 0.92$ \\
\hline & Which style will you choose when you dress yourself up? & $3.29 \pm 0.82$ \\
\hline \multirow[t]{2}{*}{ Dietary habits } & Will you choose Guangdong food when you cook? & $2.52 \pm 0.96$ \\
\hline & Which kind of food do you like most in your daily life? & $2.61 \pm 1.00$ \\
\hline \multirow[t]{2}{*}{ Life pressure } & Do you think life in Guangzhou was more stressful? & $2.59 \pm 1.83$ \\
\hline & Do you like the life pace in Guangzhou? & $2.79 \pm 1.35$ \\
\hline \multirow[t]{4}{*}{ Entertainment } & Do you like to watch TV programme in Cantonese? & $3.36 \pm 1.46$ \\
\hline & Do you like to listen songs in Cantonese? & $3.16 \pm 1.46$ \\
\hline & Did you focus on news of Guangzhou instead of your hometown? & $4.08 \pm 0.95$ \\
\hline & Do you prefer entertainment of Guangzhou in your spare time? & $3.16 \pm 0.97$ \\
\hline \multirow[t]{2}{*}{ Social interaction } & Where does your closest friend come from? & $2.41 \pm 1.18$ \\
\hline & Where does the friend who can make you feel most comfortable come from? & $2.34 \pm 1.23$ \\
\hline \multirow[t]{4}{*}{ Self-identity } & Where do you think you belong to? & $1.88 \pm 1.14$ \\
\hline & Do you feel depressed when someone calls you outlander? & $2.98 \pm 0.48$ \\
\hline & Are you satisfied with your life in Guangzhou? & $3.80 \pm 0.79$ \\
\hline & Do you want to stay in Guangzhou the rest of your life? & $3.62 \pm 0.84$ \\
\hline
\end{tabular}

methods of parents' acculturation and divided into two levels (cut by 50 points).

\section{Data analysis}

First, we described the demographic and migration characteristics of the children and their parents, health services utilisation of IM children and their parents' acculturation using descriptive statistics by means, SD, frequency and proportion. Second, we applied correlation and bivariate logistic regression to check the relationship between children's HSU and their parents' acculturation. Finally, we assessed the association between IM children's HSU and parents' acculturation by performing a multivariable logistic regression model. In addition, family economic status was an important factor of enabling factors and proved to be associated with HSU, while IMs commonly had economic difficulties; we thus checked the moderation effect of family economic status on the association between IM children's HSU and their parents' acculturation by stratified analysis using the multivariable logistic regression model. The independent variables were chosen if they had a $\mathrm{P}$ value below the threshold of 0.1 shown in correlation analysis or were proved to have critical association with children's HSU in the majority of studies, ${ }^{134445}$ and then the multivariable logistic regression was conducted using an enter method, including all selected confounding variables and parents' acculturation level. In addition, we explored the moderation effects of family economic status on the association between IM children's HSU and their parents' acculturation by multivariable logistic regression using the method of enter as well.

Each correlation analysis and logistic regression analyses included a chi-statistic and Wald test with a two-side significance of 0.05 . We assessed the association and moderation effect by unadjusted OR and adjusted OR (AOR) and their 95\% CIs. We excluded participants with 
missing data on HSU and participants with more than $1 / 3$ items missing on parent's acculturation; otherwise, we completed the missing data by a combined method of hot-deck imputation and conditional mean completer. The sensitivity analyses were conducted to compare results using the combined imputation method with those using the multiple imputation. All analyses were performed using IBM SPSS statistics, V.20.0.

\section{Ethics and consent}

We introduced the purpose of this survey to the students face to face, while the trained students further explained the purposes of the study to their caregivers with help of the introduction as appearing at the beginning of the questionnaires. Small gifts were given to the participants who completed this survey. Written consents were sought from all the participants. All the participants completed this survey on the voluntary basis. All the questionnaires were anonymous and stored in a secured room only open to the research members and data administrators.

\section{RESULTS}

\section{Participants' characteristics}

In total, we surveyed 1199 children and one of their main caregivers (ratio 1:1) who matched the selection criteria. Of them, 1161 pairs $(96.8 \%)$ completed the questionnaires (the main caregivers were parents), and 258 children were in need of outpatient or inpatient health service. The missing data of all variables interested was between $0.3 \%$ and $9.6 \%$. Specifically, 216 children $(18.6 \%$ of the total IM children) were ill within the past 2 weeks and so defined as being in need of outpatient service; 94 children $(8.1 \%$ of the total IM children) were in need of inpatient service. Children in need of inpatient service

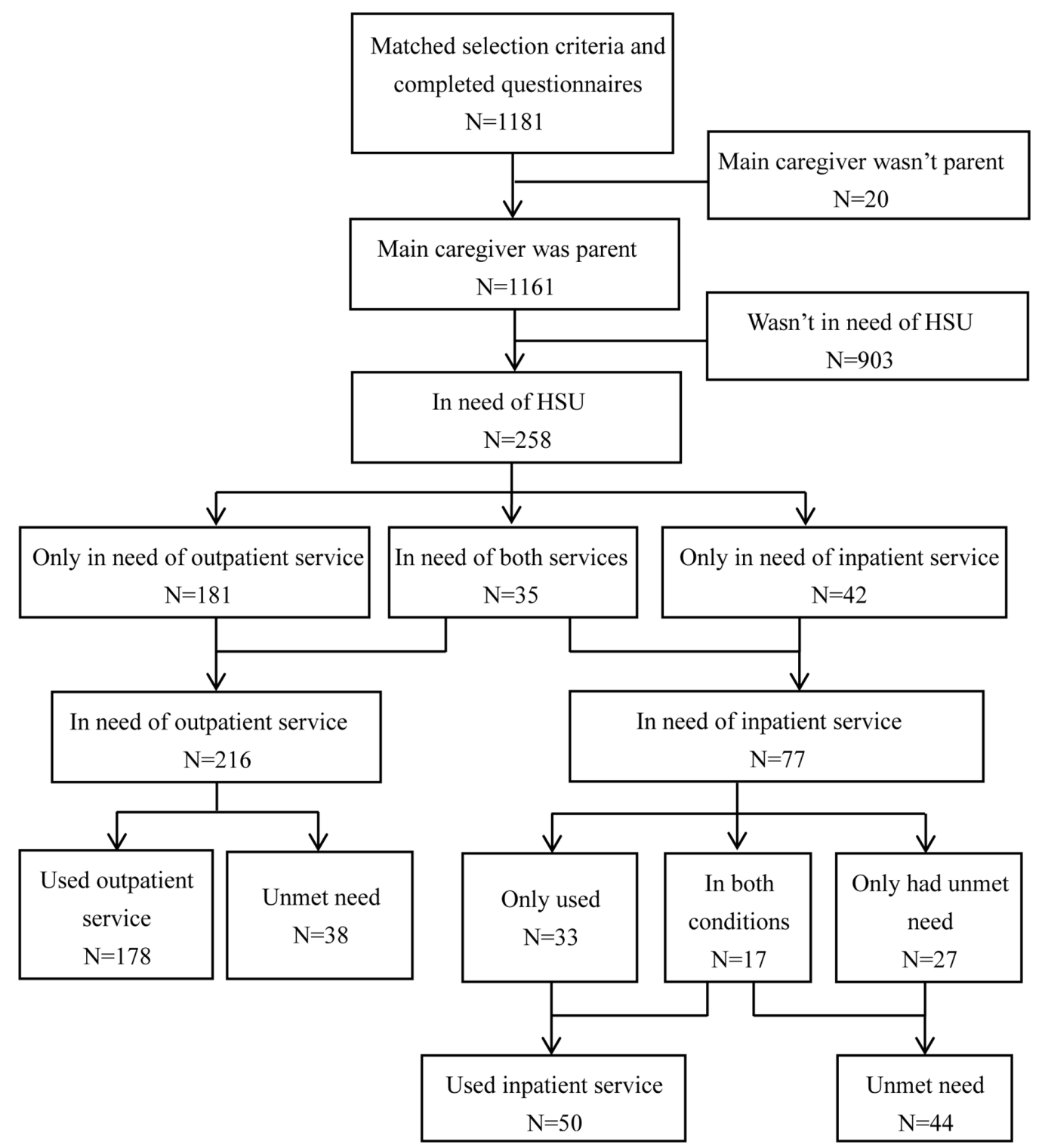

Figure 1 Flow chart of included internal migrant children and their parents for analysis in this study. HSU, health service utilisation. 
were defined as those who used inpatient service or who were asked by a doctor to be hospitalised during the past year (figure 1 ).

Table 2 described the characteristics of IM children and their parents. Most children in need of outpatient service were less than 15 years old $(78.2 \%)$, boys $(56.5 \%)$, not living with their grandparents $(89.8 \%)$, in poorer family economic status that scored less than $50(73.6 \%)$ and not enrolled in the public health insurance schemes in Guangzhou $(63.9 \%)$. Most parents of children who were in need of outpatient service were older than 40 years $(72.2 \%)$, married $(95.4 \%)$, at lower level of education (75.9\% parents did not finish senior high school), staying in Guangzhou between 10 and 20 years (54.2\%) and did not have to work during the opening hours of health facilities $(67.1 \%)$. About half of them $(50.5 \%)$ had a physical check-up during the past year.

Parents and children who were in need of inpatient service had characteristics that were similar to those needing outpatient service. However, they had better enabling resources: $41(43.6 \%)$ children's family economic status scored over 50 and 51 (54.3\%) children were enrolled in health insurances of Guangzhou.

\section{IM children's HSU}

Children who visited a doctor within the past 2 weeks accounted for $82.4 \%$ (178/216), and the proportion of children who had an unmet need for outpatient service(defined as not using any health service) was $17.6 \%(38 / 216)$. Characteristics between the IM children who used and who had an unmet need of outpatient service within the past 2 weeks were significantly different regarding family economic score $(\mathrm{P}=0.015)$ and parents' physical check-up in the previous year $(\mathrm{P}=0.005$, table 2$)$.

In the last year, $46.8 \%$ (44/94) IM children had an unmet inpatient service need (who were asked by a doctor to be hospitalised but did not actually use inpatient service). IM children who used the inpatient service during the last year were significantly younger than those who had an unmet need ( $\mathrm{P}=0.029$, table 2$)$.

\section{Acculturation situation of the IM parents}

Overall, the IM parents whose children were in need of health services had a mean score of $53(\mathrm{SD}=18)$ in acculturation, while the middle level of acculturation was between 46.62 and 61.40 as mentioned above. Results in table 3 showed the correlation of the four dimensions and parents' acculturation. Parents' language proficiency $(63, \mathrm{SD}=16)$ was the most important dimension of acculturation, followed by social interaction $(39, \mathrm{SD}=24)$, lifestyle adaptation $(43, \mathrm{SD}=15)$ and self-identify (44, $\mathrm{SD}=14)$.

As a categorical variable, parents' acculturation status was statistically different between children who used and who had an unmet need for outpatient service $(\mathrm{P}=0.040$, table 4).
Association between IM children's HSU and parents' acculturation

After adjusting for the confounding factors of predisposing characteristics (including parents' marital status and physical check-up behaviours in the previous year) and enabling resources factors, the multivariate logistic regression (model 1 of table 5) indicated that IM children whose parents were in the middle-level acculturation group were less likely to use outpatient service compared with children whose parents were in the low-acculturation or high-acculturation group, although it was only significant when compared with the high-acculturation group. IM children with middle-acculturation group parents ( $\mathrm{AOR}=3.17,95 \%$ CI 1.2 to $8.3, \mathrm{P}<0.05)$ were more likely to have an unmet need after being sick within the past 2 weeks compared with the children with high-acculturation group's parents. When we changed the imputation method to the multiple imputation, the sensitivity analyses showed similar results.

The stratified analysis showed that association of parents' acculturation level and children's outpatient service utilisation was inconsistent between different subgroups of family economic status. Similar to the total subjects, the association in the subgroup of poorer family economic status (scored less than 50) was a U-shape curve (figure 2). This indicates that IM children whose parents were in the middle-acculturation group were more likely to have an unmet need for outpatient service compared with those whose parents were in the low-acculturation or high-acculturation group. However, it was only significant (AOR=3.82, 95\% CI 1.2 to $12.2, \mathrm{P}<0.05)$ when compared with children whose parents were in the low-acculturation group (model 2 of table 5). In the subgroup whose family economic status was better (scored more than 50), the association between IM children's outpatient service utilisation and their parents' acculturation was positive, although it was only significant in children whose parents were in the low-acculturation group (AOR $=13.51$, 95\% CI 1.6 to $117.0, \mathrm{P}<0.05$ ) compared with those in the highacculturation group (model 3 of table 5). Table 6 indicated that compared with other groups, parents in both low-acculturation and poor economic status were more likely to use private clinics (26.8\% vs $13.9 \%$ ) while less likely to use governmental health facilities $(62.5 \%$ vs $80.3 \%$ ).

The multivariate logistic regression of IM children's inpatient service utilisation and their parents' acculturation did not show statistical significance. Results of the bivariate logistic regression between these two variables showed no statistical significance. However, the rates of unmet inpatient service need among children whose parents were in the middle-acculturation group were lower than others, which was inconsistent with the association on outpatient service utilisation and indicated the complementary association between outpatient and inpatient services sometimes (table 7). 


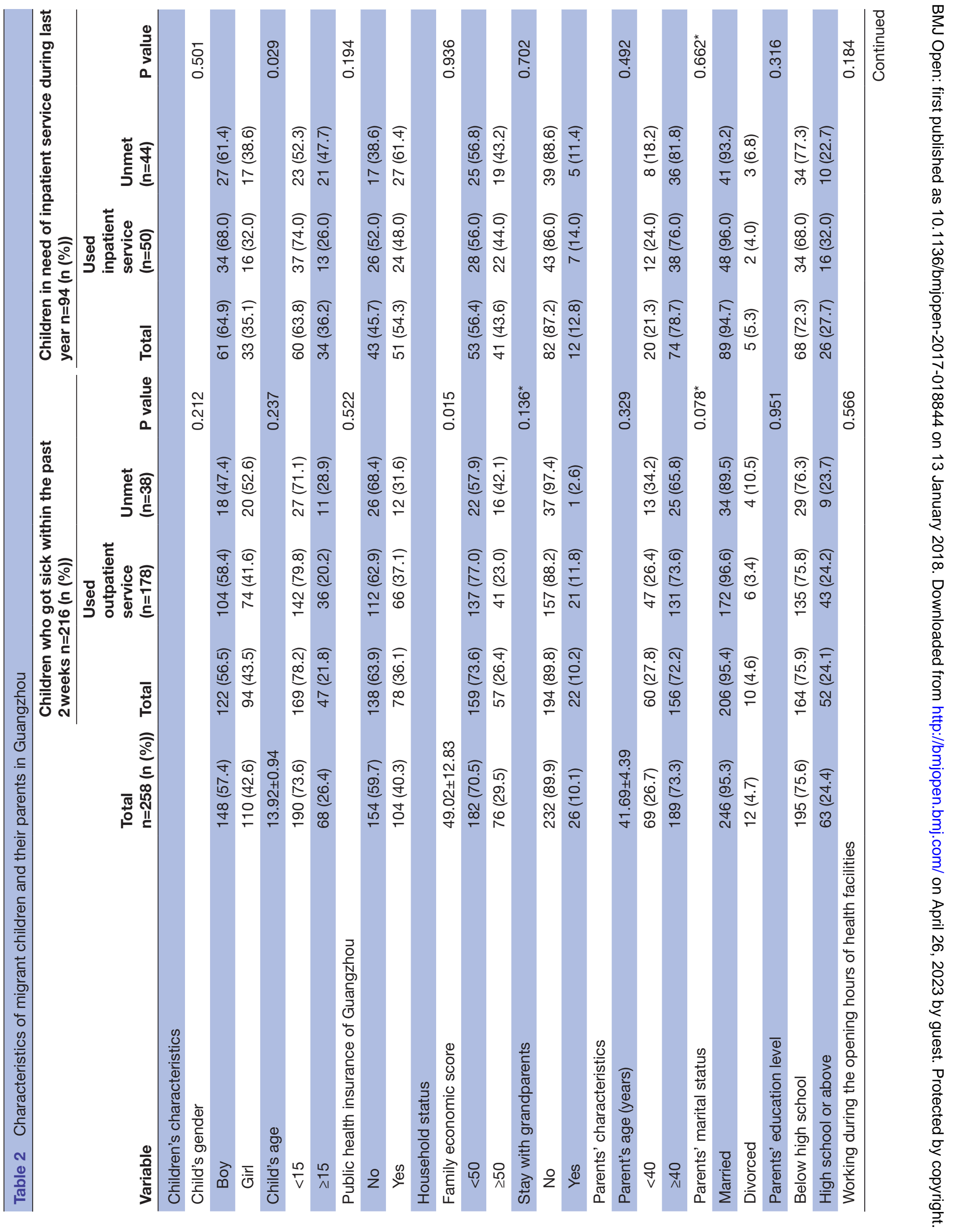




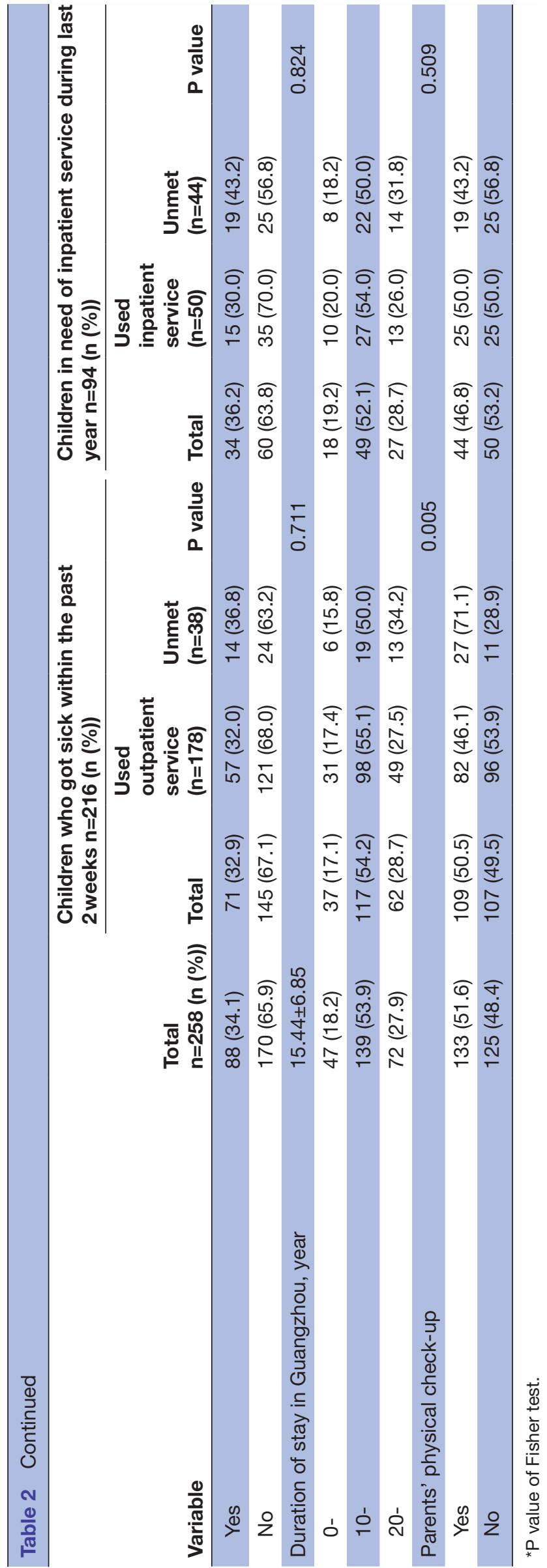

\section{DISCUSSION}

This study is one of the first research to explore the association between IM children's HSU and their parents' acculturation, using comprehensive variables to measure acculturation among IMs. Our study suggested that the association between parents' acculturation and children's HSU was complex and non-linear and could be moderated by family economic status.

Our study suggested that compared with those in the high-acculturation group, parents in the middleacculturation group were less likely to use outpatient health service while their children were sick, which was consistent with findings from previous research among international immigrant children. ${ }^{18} 192146$ However, language proficiency, as one of the most important dimensions, did not affect the communication between IMs and doctors but acted as a sign of frequent interactions with the local residents, which was inconsistent with the previous studies on international immigrants. ${ }^{18} 192146$ Consequently, the association between IM children's outpatient service utilisation and parents' acculturation can be explained as follows. One possible reason may be that parents' perceived personal and societal discrimination, which was negatively associated with acculturation, would influence their trust on health services. ${ }^{47}$ Hence, parents in the middle-acculturation group perceived more discrimination and medical mistrust compared with those parents in the high-acculturation group, which prevented them from using outpatient service after their children were ill. Additionally, the parents in the highacculturation group tended to have better health awareness and behaviours, ${ }^{48-51}$ which enabled them to take their children to visit doctors in the beginning of the illness and to use more preventive health services. Parents in the high-acculturation group also had better social interaction, which would enable them to gain necessary information about the health service system and to receive outpatient service more easily.

Besides, the association of IM children's outpatient service utilisation and parents' acculturation between different family economic subgroups was inconsistent. In the subgroup of poorer family economic status (scored less than 50 for average family monthly income, occupation and residence), IM children whose parents were in the middle-acculturation group had a higher proportion of unmet need for outpatient service compared with those in the low-acculturation and high-acculturation groups (shown in figure 2). This pattern was similar to that of the results of the main study, although only the comparison with children whose parents were in the low-acculturation group had reached statistical significance. Another study also found IM workers in lower socioeconomic group used more health service. ${ }^{52}$ The reason may be that parents in both low-acculturation group and poor economic status may have poor awareness towards their children's health status, which may cause the underdetection of any illnesses. ${ }^{53}$ In addition, children in seventh and eighth grade were more likely to have cold 
Table 3 Mean score of four dimensions between different groups of acculturation

\begin{tabular}{lllllll}
\hline & & \multicolumn{4}{c}{ Average score (means \pm SD) } \\
\cline { 3 - 7 } Acculturation group & $\mathbf{n}$ & Acculturation & Social interaction & $\begin{array}{l}\text { Lifestyle } \\
\text { adaptation }\end{array}$ & Self-identity & $\begin{array}{l}\text { Language } \\
\text { proficiency }\end{array}$ \\
\hline Low & 89 & $33.04 \pm 11.03$ & $22.23 \pm 19.39$ & $33.97 \pm 12.95$ & $36.04 \pm 9.84$ & $47.38 \pm 13.24$ \\
Middle & 81 & $54.34 \pm 4.27$ & $42.08 \pm 21.63$ & $42.78 \pm 12.19$ & $43.89 \pm 12.53$ & $64.45 \pm 8.55$ \\
High & 88 & $71.23 \pm 8.07$ & $54.48 \pm 18.98$ & $51.32 \pm 15.34$ & $51.84 \pm 14.92$ & $77.71 \pm 8.44$ \\
Total & 258 & $52.76 \pm 17.93$ & $39.46 \pm 24.05$ & $42.65 \pm 15.34$ & $43.89 \pm 14.15$ & $63.08 \pm 16.32$ \\
$\begin{array}{l}\text { Pearson correlation } \\
\text { coefficient }\end{array}$ & & & 0.578 & 0.562 & 0.479 & 0.892 \\
\hline
\end{tabular}

Low acculturation included parents who scored 0-46.61; middle acculturation included parents who scored 46.62-61.40; high-acculturation included parents who scored 61.41-100.

or diarrhoea instead of some serious illnesses, which may often be managed through self-medication. ${ }^{54-56}$ However, parents in the low-acculturation group were more likely to have limited knowledge to implement successful selfmedication, thereby choosing to use outpatient service after their children got ill. ${ }^{57}$ Although parents in the low-acculturation group and poor economic status had a higher rate of outpatient service utilisation, the health facilities they chose were more likely to be society-run clinics $(26.8 \%$, the so-called private clinics), which generally have poorer service quality and lower medical expenditure without a licence ${ }^{58}$ instead of governmental health facilities, compared with other groups. This proportion was even higher than that among the IM workers in one study, which found that $20 \%$ IM workers selected the society-run clinic to see a doctor. ${ }^{58}$ This suggested that although children in poorer family economic and low acculturation status had better utilisation, the quality of services they received was worse.

However, in the subgroup of better family economic status (scored 50 or more), the association between children's outpatient service utilisation and their parents' acculturation was positive, which was generally consistent with other studies. ${ }^{18192146}$ Results on the association of outpatient service utilisation and acculturation recommend the government to improve both IMs' acculturation and economic status, to prolong the opening time of outpatient department or provide evening clinics and to focus on outpatient service utilisation of the IM children whose parents have little interaction with the native population. Measures to promote the IMs' acculturation may include weakening the barrier of household registration, eliminating discrimination against IMs and promoting the coverage of local public health insurance.

However, we did not find any statistical association between parents' acculturation level and their children's inpatient service utilisation, which was consistent with previous research. ${ }^{59}$ This might suggest that enabling resources played a more important role in explaining the inpatient service utilisation than the parents' acculturation. Hence, in order to decrease the unmet need for inpatient service, we should mainly focus on enabling resources and should take measures to improve the economic status of IMs and to reduce their work pressure.

Although the association between IM children's inpatient service and their parents' acculturation was nonsignificant, our study suggested that IM children whose parents were in the middle-acculturation group had a lower level of unmet needs, in other words, they had better utilisation of inpatient service compared with the other groups, which was in contrast with the associations between acculturation and outpatient service utilisation. This may also suggest the complementary association between outpatient and inpatient service utilisation. ${ }^{6061}$

Table 4 Correlation of IM parents' acculturation and their children's HSU

Children who got sick within the past 2 weeks $n=216$ (n (\%))

\begin{tabular}{|c|c|c|c|c|c|c|c|}
\hline \multirow[b]{2}{*}{ Variable } & \multirow[b]{2}{*}{$\begin{array}{l}\text { Total } \\
\mathrm{n}=258 \text { (n (\%)) }\end{array}$} & & \\
\hline & & $\begin{array}{l}\text { Used outpatient } \\
\text { service }(n=178)\end{array}$ & $\begin{array}{l}\text { Unmet } \\
(n=38)\end{array}$ & $P$ value & $\begin{array}{l}\text { Used inpatient } \\
\text { service }(n=50)\end{array}$ & $\begin{array}{l}\text { Unmet } \\
(n=44)\end{array}$ & $P$ value \\
\hline Acculturation & $52.76 \pm 17.93$ & $52.96 \pm 18.31$ & $52.80 \pm 15.26$ & 0.961 & $53.21 \pm 16.38$ & $53.67 \pm 18.44$ & 0.898 \\
\hline Low & 89 (34.5) & $63(35.4)$ & 12 (31.6) & & $12(24.0)$ & $14(31.8)$ & \\
\hline Middle & $81(31.4)$ & $49(27.5)$ & $18(47.4)$ & & $22(44.0)$ & $14(31.8)$ & \\
\hline
\end{tabular}

IM, internal migrant; HSU, health service utilisation. 
Table 5 Factors related to the unmet outpatient service need within the past 2 weeks

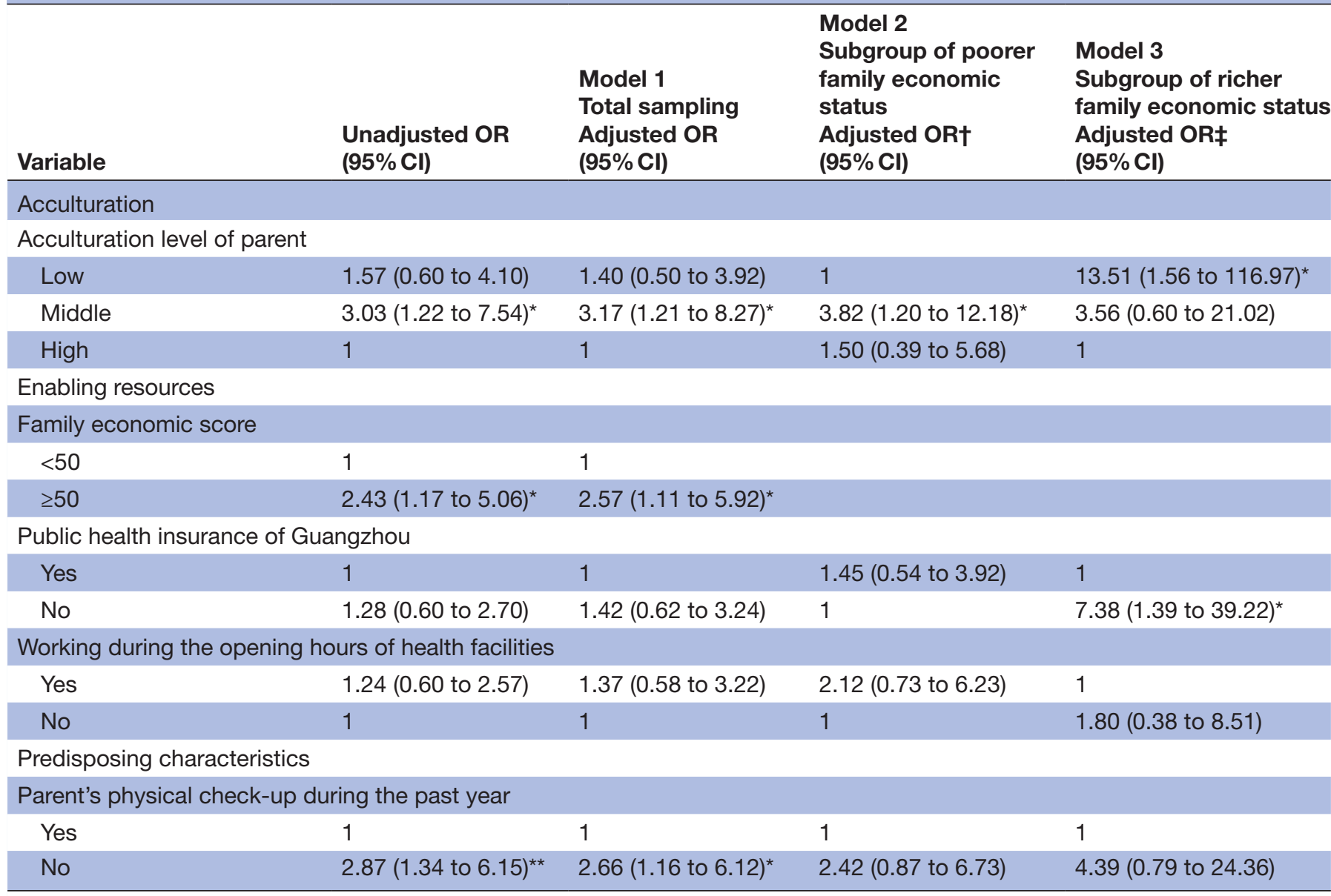

${ }^{*} \mathrm{P}<0.05 ;{ }^{* *} \mathrm{P}<0.01$.

†Adjusted OR: subgroup whose family economic status scored less than 50.

$\ddagger$ Adjusted OR: subgroup whose family economic status scored 50 and higher.

There are several limitations in this study. First, the cross-sectional survey did not allow for the exploration of the causal relationship between variables. However, our results may inform the future intervention studies to improve the IM children's health services utilisation. Second, the small sample size had limited the power

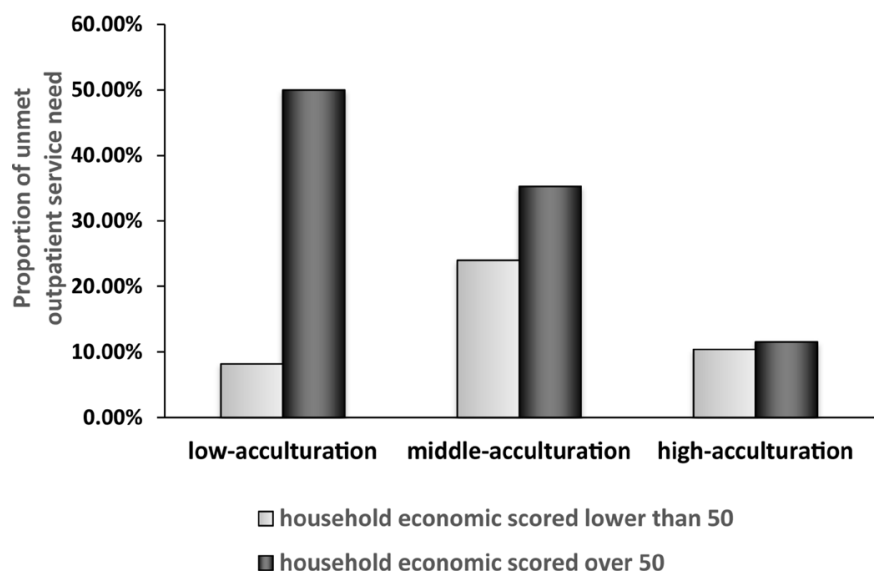

Figure 2 Moderation of family economic status on the association between IM children's outpatient service utilisation and their parents' acculturation.
Table 6 Health facilities that parents visited after their children were ill

\begin{tabular}{|c|c|c|}
\hline Health facilities & $\begin{array}{l}\text { Low acculturation and } \\
\text { poor economic status } \\
n=56(n(\%))\end{array}$ & $\begin{array}{l}\text { Others } \\
n=122(n(\%))\end{array}$ \\
\hline Private clinics & $15(26.8)$ & 17 (13.9) \\
\hline $\begin{array}{l}\text { Governmental } \\
\text { health facilities }\end{array}$ & $35(62.5)$ & $98(80.3)$ \\
\hline Others & $1(1.8)$ & $3(2.5)$ \\
\hline Missing data & $5(8.9)$ & $4(3.3)$ \\
\hline
\end{tabular}

and made it difficult to detect the influence of many other factors, such as children's gender, parents' age and parents' education level, but these variables in this study had no statistical difference between various groups of IM children in need. Third, the Cronbach's alpha of the self-identity dimension of acculturation was low, which would affect the internal consistency of this dimension. However, the Cronbach's alpha of the total acculturation was acceptable, and our study analysed parents' acculturation in whole rather than in its 
Table 7 Determination of the unmet inpatient need during the past year

\begin{tabular}{llll}
\hline Variable & $\begin{array}{l}\text { Total } \\
(\mathbf{n = 9 4 )}\end{array}$ & $\begin{array}{l}\text { Rate of unmet Unadjusted OR } \\
\text { need }(\%)\end{array}$ & \\
\hline $\begin{array}{l}\text { Acculturation } \\
\text { Acculturation }\end{array}$ & & & \\
$\begin{array}{l}\text { Accul of parent } \\
\text { level }\end{array}$ & & & $1.17(0.41$ to 3.29$)$ \\
\hline Low & 26 & 53.8 & $0.64(0.24$ to 1.67$)$ \\
\hline Middle & 36 & 38.9 & 1 \\
\hline High & 32 & 50.0 & \\
\hline
\end{tabular}

individual dimensions, so that the measurement is still considered reliable. Fourth, the generalisation of results may be limited since this study was only conducted in the society-run schools in two districts with high proportions of IMs due to the logistical constraints. Finally, the HSU was measured by parents' self-reported questions, which may have reported bias of health conditions (in need of service) and also utilisation. In addition, since we failed to collect information about health belief, it was proximately measured by physical check-up during the past 12 months. Despite a health behaviour indicator, it still well reflects the health belief according to the health belief model. ${ }^{39} 40$ Despite these limitations, our study explored the non-linear association between IM children's HSU and their parents' acculturation and indicated the moderation effect of family economic status on this association.

In conclusion, the association between IM children's outpatient service utilisation and their parents' acculturation was complex and could be moderated by family economic status. IM children whose parents were in the middle-acculturation group were less likely to use outpatient service compared with those whose parents were in low-acculturation and high-acculturation groups, although only the comparison with the high-acculturation group was statistically significant. This result indicated that research on the association between IMs' acculturation and their children's HSU would be non-linear, and in order to intensively explore the association between these two variables, future research may need to modify their models. Besides, IM children whose parents were in both low-acculturation and poor economic status were more likely to use outpatient service but chose the poorer quality and cheaper service provided by society-run clinics instead of governmental health facilities. This suggested that the main issue was diverse between different acculturated groups, and future research should focus on the access and the quality of health service IMs received. In order to increase IMs' HSU, we should improve both IMs' acculturation and economic status, which also take important roles in increasing their access to the better medical environment in the low-acculturation and poor IMs. However, this study did not find any association between IM children's inpatient service utilisation and their parents' acculturation, which should be confirmed in a larger sample.

Acknowledgements We acknowledge Zhang Qi (Old Dominion University and Sun Yat-sen University) for his contribution in designing questionnaire of this study. We also acknowledge Long-Tao Secondary School, Qi-Ming Secondary School and Jing-Yuan Secondary School in Baiyun district; and Long-Tao Secondary School, Long-Shen Secondary School and Dong-Feng Secondary School in Tianhe district for the assistance in data collection.

Contributors BP conceptualised this paper, conducted statistical analyses and drafted the initial manuscript. LL conceptualised this study and the paper and critically revised this paper. GZ was involved in the development of the paper and provided critical comments and revision of the paper. WC was involved in the development of the structure and critically revised this paper. YL was involved in the design of this study and collected the data. All authors contributed to the manuscript and approved the final manuscript.

Funding This research received no specific grant from any funding agency in the public, commercial or not-for-profit sectors.

Competing interests None declared.

Patient consent Obtained.

Provenance and peer review Not commissioned; externally peer reviewed.

Data sharing statement No additional data are available.

Open Access This is an Open Access article distributed in accordance with the Creative Commons Attribution Non Commercial (CC BY-NC 4.0) license, which permits others to distribute, remix, adapt, build upon this work non-commercially, and license their derivative works on different terms, provided the original work is properly cited and the use is non-commercial. See: http://creativecommons.org/ licenses/by-nc/4.0/

(c) Article author(s) (or their employer(s) unless otherwise stated in the text of the article) 2018. All rights reserved. No commercial use is permitted unless otherwise expressly granted.

\section{REFERENCES}

1. Department Of Service And Management of Migrant Population National Health and Family Planning Commission of China. Report on China's migrant population development 2016. Beijing: China: Population Publishing House, 2016.

2. Population Census Office under the State Council Department of Population and Employment Statistics National Bureau of Statistics. Tabulation on the 2010 population census of the people republic of China. Beijing, China: Statistics Press, 2013.

3. Mou J, Griffiths SM, Fong HF, et al. Defining migration and its health impact in China. Public Health 2015;129:1326-34.

4. Jahn HJ, Ling L, Han L, et al. Migration and health in megacities: a Chinese example from Guangzhou, China. health in megacities and urban areas. Berlin: Berlin Heidelberg: Springer, 2011:189-208.

5. Qiu P, Yang Y, Zhang J, et al. Rural-to-urban migration and its implication for new cooperative medical scheme coverage and utilization in China. BMC Public Health 2011;11:520.

6. Zhang J, Lin S, Liang D, et al. Public health services utilization and its determinants among internal migrants in china: evidence from a nationally representative survey. Int $J$ Environ Res Public Health 2017;14:1002.

7. Lam KK, Johnston JM. Health insurance and healthcare utilisation for Shenzhen residents: a tale of registrants and migrants? BMC Public Health 2012;12:868.

8. Liu S, Hu CX, Mak S. Comparison of health status and health care services utilization between migrants and natives of the same ethnic origin-the case of Hong Kong. Int J Environ Res Public Health 2013;10:606-22.

9. Gu H, You H, Ning W, et al. Internal migration and maternal health service utilisation in Jiangsu, China. Trop Med Int Health 2017;22:124-32.

10. Hu X, Cook S, Salazar MA. Internal migration and health in China. The Lancet 2008;372:1717-9.

11. Lu L, Zeng J, Zeng Z. Demographic, socio-economic, and health factors associated with use of health services among internal migrants in China: an analysis of data from a nationwide crosssectional survey. The Lancet 2016;388:S5.

12. Jarlenski M, Baller J, Borrero S, et al. Trends in disparities in lowincome children's health insurance coverage and access to care by family immigration status. Acad Pediatr 2016;16:208-15. 
13. Ku L. Improving health insurance and access to care for children in immigrant families. Ambul Pediatr 2007;7:412-20.

14. Javier JR, Wise PH, Mendoza FS. The relationship of immigrant status with access, utilization, and health status for children with asthma. Ambul Pediatr 2007;7:421-30.

15. Ku L, Matani S. Left out: immigrants' access to health care and insurance. Health Aff 2001;20:247-56.

16. Thomson MD, Hoffman-Goetz L. Defining and measuring acculturation: a systematic review of public health studies with Hispanic populations in the United States. Soc Sci Med 2009;69:983-91.

17. Abraído-Lanza AF, Chao MT, Flórez KR. Do healthy behaviors decline with greater acculturation? Implications for the Latino mortality paradox. Soc Sci Med 2005;61:1243-55.

18. Flores G, Abreu M, Tomany-Korman SC. Why are Latinos the most uninsured racial/ethnic group of US children? A community-based study of risk factors for and consequences of being an uninsured Latino child. Pediatrics 2006;118:e730-740.

19. Nieves RM. The influence of acculturation and other family characteristics on asthma outcomes in Hispanic children. Tampa, Florida: University of South Florida, 2007

20. Yu SM, Bellamy HA, Schwalberg RH, et al. Factors associated with use of preventive dental and health services among U.S. adolescents. J Adolesc Health 2001;29:395-405.

21. Quandt SA, Clark HM, Rao P, et al. Oral health of children and adults in Latino migrant and seasonal farmworker families. J Immigr Minor Health 2007;9:229-35.

22. Ismail Al, Szpunar SM. Oral health status of Mexican-Americans with low and high acculturation status: findings from southwestern HHANES, 1982-84. J Public Health Dent 1990;50:24-31.

23. Perreira KM, Bucsan C. Latino immigrant parents: accessing mental health services for their adolescents. Carolina: Carolina Population Center, 2015. http://www.cpc.unc.edu/projects/lamha

24. Marin G, Sabogal F, Marin BV. Development of a short acculturation for Hispanics (SASH) scale. Hisp J Behav Sci 1987;2:183-205.

25. Fang L, Sun RCF, Yuen M. Acculturation, economic stress, social relationships and school satisfaction among migrant children in Urban China. J Happiness Stud 2016;17:507-31.

26. Berry JW. Immigration, acculturation, and adaptation. Applied Psychology 1997;46:5-34.

27. Juhua Y. Index of assimilation for rural-to-urban migrants: a further analysis of the conceptual framework of assimilation theory. Population \& Economics 2010;2:64-70.

28. Hao Z. Measurement and theoretical perspectives of immigrant assimilation in China. Population Research 2012;36:27-37.

29. Nasuuna E, Santoro G, Kremer P, et al. Examining the relationship between childhood health conditions and health service utilisation at school entry and subsequent academic performance in a large cohort of Australian children. J Paediatr Child Health 2016;52:750-8.

30. Aday LA, Andersen R. A framework for the study of access to medical care. Health Serv Res 1974;9:208-20.

31. Andersen RM. Revisiting the behavioral model and access to medical care: does it matter? J Health Soc Behav 1995;36:1-10.

32. Yang $P Q$, Hwang SH. Explaining immigrant health service utilization. Sage Open 2016;6:1-5.

33. Song XL, Zou GY, Shi JR, et al. Health service utilization of internal migrants in Guangdong province:from the family migration perspective. Modern Preventive Medicine 2017.

34. Liu ZY, Li J, Hong Y, et al. Reproductive health service utilization and social determinants among married female rural-to-urban migrants in two metropolises, China. J Huazhong Univ Sci Technolog Med Sci 2016;36:904-9.

35. Xu H, Luo J, Wu B. Self-reported diabetes treatment among Chinese middle-aged and older adults with diabetes: Comparison of urban residents, migrants in urban settings, and rural residents. Int $J$ Nurs Sci 2015;2:9-14.

36. Fan JX, Wen M, Jin L, et al. Disparities in healthcare utilization in China: do gender and migration status matter? J Fam Econ Issues 2013;34:52-63.

37. Guangzhou Bureau of Statistics. The sixth national population census of Guangzhou t1-04, 2013. http://www.gzstats.gov.cn/pchb/ rkpc6/t1-04.htm

38. Guangzhou Bureau of Statistics. Statistical yearbook 2016, 2016. in: http://data.gzstats.gov.cn/gzStat1/chaxun/njsj.jsp
39. Becker M. The health belief model and personal health behavior. Health Educ Monogr 1974;2:287-312.

40. Leavitt $F$. The health belief model and utilization of ambulatory care services. Soc Sci Med Med Psychol Med Sociol 1979;13A:105-12.

41. Birman D, Trickett EJ, Vinokurov A. Acculturation and adaptation of soviet jewish refugee adolescents: predictors of adjustment across life domains. Am J Community Psychol 2002;30:585-607.

42. Szapocznik J, Scopetta MA, King OE. Theory and practice in matching treatment to the special characteristics and problems of Cuban immigrants. J Community Psychol 1978;6:112-22.

43. Wenhong Z, Kaichun L. The urban new immigrants' social inclusion: internal structure, present situation and influential factors. Sociological Studies 2008;5:117-41.

44. Onyejaka NK, Folayan MO, Folaranmi N. Barriers and facilitators of dental service utilization by children aged 8 to 11 years in Enugu State, Nigeria. BMC Health Serv Res 2016;16:93

45. Cassedy A, Fairbrother G, Newacheck PW. The impact of insurance instability on children's access, utilization, and satisfaction with health care. Ambul Pediatr 2008;8:321-8.

46. De Jesus M, Xiao C. Cross-border health care utilization among the hispanic population in the United States: implications for closing the health care access gap. Ethn Health 2013;18:297-314

47. Renzaho A, Polonsky M, McQuilten Z, et al. Demographic and socio-cultural correlates of medical mistrust in two Australian States: Victoria and South Australia. Health Place 2013;24:216-24.

48. Coups EJ, Stapleton JL, Hudson SV, et al. Linguistic acculturation and skin cancer-related behaviors among hispanics in the southern and western United States. JAMA Dermatol 2013;149:679-86.

49. McNeill LH, Stoddard A, Bennett GG, et al. Influence of individual and social contextual factors on changes in leisure-time physical activity in working-class populations: results of the healthy directions-small businesses study. Cancer Causes Control 2012;23:1475-87.

50. Kim SS, Nguyen HL, Le TH. Culture and smoking among vietnamese americans in central massachusetts. J Transcult Nurs 2012;23:151-8.

51. Smith-Greenaway E, Madhavan S. Maternal migration and child health: an analysis of disruption and adaptation processes in benin. Soc Sci Res 2015;54:146-58.

52. Zou G, Zeng Z, Chen W, et al. Self-reported illnesses and service utilisation among migrants working in small-to medium sized enterprises in Guangdong, China. Public Health 2015;129:970-8.

53. Kietzmann D, Hannig C, Schmidt S. Migrants' and professionals' views on culturally sensitive pre-hospital emergency care. Soc Sci Med 2015;138:234-40.

54. Bertoldi AD, Silveira MP, Menezes AM, et al. Tracking of medicine use and self-medication from infancy to adolescence: 1993 Pelotas (Brazil) birth cohort study. J Adolesc Health 2012;51:S11-15.

55. Valenzuela Ortiz M, Sánchez Ruiz-Cabello FJ, Uberos J, et al. [Self-medication, self-prescription and medicating "by proxy» in paediatrics]. An Pediatr 2017;86:264-9.

56. Bham SQ, Saeed F, Shah MA. Knowledge, attitude and Practice of mothers on acute respiratory infection in children under five years. Pak J Med Sci 2016;32:1557-61.

57. Kietzmann D, Knuth D, Schmidt S. (Non-)utilization of pre-hospital emergency care by migrants and non-migrants in Germany. Int $J$ Public Health 2017;62:95-102.

58. Peng Y, Chang W, Zhou H, et al. Factors associated with healthseeking behavior among migrant workers in Beijing, China. BMC Health Serv Res 2010;10:69.

59. Xu KT, Borders TF. Does being an immigrant make a difference in seeking physician services? J Health Care Poor Underserved 2008;19:380-90.

60. Jian WY, Fang $\mathrm{H}$. [An empirical analysis on the substitution effect of outpatient services on inpatient services]. Beijing Da Xue Xue Bao Yi Xue Ban 2015;47:459-63.

61. Jing MX, Li XJ, Jian WY. Preventing fatal risk through outpatient medical insurance: evidence from urban employee basic medical insurance system in Xinjiang Uighur autonomous region, China. Biomed Environ Sci 2014;27:544-51. 